\title{
How to Improve Field Tennis Flat Serve Skills through Differences Training Methods, Form of Stretching, and Grip Strength?
}

\author{
Muhammad Mariyanto ${ }^{1}$, Sugiharto² ${ }^{2}$, Soegiyanto $\mathrm{KS}^{2}$, Agus Kristiyanto ${ }^{3}$, TaufikHidayah ${ }^{4}$, \\ Efa Nugroho 5 \\ ${ }^{1}$ Researcher, Post Graduate Program, Universitas Negeri Semarang, Indonesia, ${ }^{2}$ Professor, Universitas Negeri \\ Semarang, Indonesia, ${ }^{3}$ Professor, Universitas Sebelas Maret Surakarta, Indonesia, ${ }^{4}$ Assoc Prof, Universitas Negeri \\ Semarang, Indonesia, ${ }^{5}$ Lecturer, Universitas Negeri Semarang, Indonesia
}

\begin{abstract}
s
For a professional who follows tournament circuit, strong serve punches are very special capital. In reality, technically the quality of blows is often inadequate. Serve punches that are carried out are very easily returned by the opponent and also do a lot of wrong serve (fault). This experimental study aims to determine the effect of training methods, forms ofexercises stretching and grip strength on the flat serve skills of tennis. This research was conducted at the Faculty of Sport of the Universitas Sebelas Maret Negeri Surakarta (UNS) in 2019. The experimental method used a 2x2x2 factorial design. The sample consisted of 80 students divided into 8 groups, each consisting of 10 students. The data analysis technique was a two-way analysis of variance (ANOVA) and continued with the Tukey test at the significance level $\alpha=0.05$. The results showed that: (1) there are significant differences between training methods overall with training methods section of the skills of serve flat tennis courts, (2) there are significant differences between the forms ofexercises stretching static form ofexercises stretching dynamically to a skill Served flats tennis the field, (3) there is a significant difference between the grip strength above the average grip strength below the average to the flat serve skills of tennis court. It can be concluded that the two types of training methods have different effects on the flat serve skills of tennis courtwhen it is associated with forms ofexercises stretching (static and dynamic) and the use of different grip strengths that are above average and below average.
\end{abstract}

Keywords: training methods, forms of training, grip strength, flat serve, tennis

\section{Background}

Achievement of optimal achievements in sports is a dream for every athlete, but to achieve this it needs careful planning through a system of systematic and continuous integrated coaching. Along with the pace of national development that is ongoing until now, the development of thesector sportsin Indonesia is directed to achieve the ideals of the nation, namely the formation of fully Indonesian people who are physically

\section{Corresponding author:}

Muhammad Mariyanto

email:muhammadmariyanto@yahoo.com and mentally healthy, and skilled so that they are able to excel in sports in order to raise dignity, dignity and degrees nation. The attention of the government is directed at efforts to disseminate sports activities as a way of fostering physical and spiritual health for each member of the community. Observing this matter, the government has ratified the Law of the Republic of Indonesia Number 3 Year 2005 concerning the National Sports System, that the sports guidance system must be carried out through 3 (three) pillars namely; educational sports, recreational sports, andsportsachievement.

In addition to systematic coaching, facilities and infrastructure as well as theenvironmentsupportingthat affect the performance of sports, factors that are not 
less important are physical condition, mental readiness, technical preparation and mastery of playing strategies. The condition of a good physical condition will affect the psychological aspectsthe inform of increased work motivation, morale, self-confidence, accuracy andso forth. Psychologically, the physical condition also seems to have a profound effect on the environment of our activities, especially in socializing. There are 4 (four) aspects of exercise training that need to be considered, namely physical preparation, technical preparation, mental / psychological preparation and tactics and strategy preparation ${ }^{1}$. All aspects or factors that have been mentioned are apparently not owned by all tennis players. There are players who only master technical skills, there are those who only have physical readiness, there are those who only have mental readinessand some who only have tactics and strategy readiness. To achieve maximum performance an athlete must master all aspects mentioned, therefore each of these factors requires special attention and treatment to achieve the desired goals. Peak of achievement can be achieved if the training management process is passed well starting from thestageplanningto the evaluation ${ }^{2}$. The management process is apart of the first very importantstage of an exercise aimed to optimize the performance of athletes in accordance with the target set. The peak achievement is aresult directof the body's adaptation to the type and method of training $\mathrm{g}^{3,4}$.

The game of tennis has a number of basic techniques that must be mastered by players, including: Serve punches, Volley, Lob, Smash andvariations other strokesuch as Approach shot, Passing shot, Dropshot and Half volley. For a professional who follows the tournament circuit, aserve stroke strongis a very special asset $^{5}$. In fact, according to observations in several tournaments, most Indonesian players were left out in the first round compared to international players.
Serve failure can also result from injury to the player ${ }^{6,7}$. It can also be caused by poor tennis racket. But most importantly technicallythe quality of the punch is inadequate, especially the lack of maximum serve punchesowned. The serve punch they do is very easy to return by the opponent and also do a lot of wrong serve (fault), meaning that the serve is not right on the serve box as a target ${ }^{8,9}$.

Various training methods have been widely applied in improving the performance of players in many sports. In learning there are several kinds of learning methods, namely the overall method, the part method,the mixed method (whole and part), and progressive method, inresearch proposal the thiswriter wants to try to apply through 2 (two) training methods, that is; (1)method overall training, and (2) part training method ${ }^{10}$. The overall training method is a method of providing training material from general to specific, such as: in practicing motion skills or serve skills in flat tennis court, then the whole form or done alone. Conversely, the section exercises method is also included that want to be applied in this study. Method training part or wholepart methods is a combined method of the training method part one on one.

The purpose of this study is to see the difference in training methods. through the application of overall and part training methods in improving theskills serveof flat tennis court by involvingfactors stretching and strengthgrip. For this reason, a deeper study of the research problem is needed so that results or answers are more reliable.

\section{Method}

The method used in this study is an experimental study using a $2 \times 2 \times 2$ factorial plan as for the design as follows: 
Table 1. Factorial Design $2 \times 2 \times 2$

\begin{tabular}{|c|c|c|c|c|c|}
\hline \multirow{2}{*}{\multicolumn{2}{|c|}{$\begin{array}{l}\text { Training Method } \\
\text { Stretching } \\
\text { (B) }\end{array}$}} & \multicolumn{2}{|c|}{ Overall (A1) } & \multicolumn{2}{|c|}{ Section (A2) } \\
\hline & & Static (B1) & Dynamic (B2) & Statc (B1) & Dynamic (B2) \\
\hline \multirow{2}{*}{ Grip Strength } & Above Average (C1) & A1B1C1 & $\mathrm{A} 1 \mathrm{~B} 2 \mathrm{C} 1$ & $\mathrm{~A} 2 \mathrm{~B} 1 \mathrm{C} 1$ & $\mathrm{~A} 2 \mathrm{~B} 2 \mathrm{C} 1$ \\
\hline & Below Average (C2) & $\mathrm{A} 1 \mathrm{~B} 1 \mathrm{C} 2$ & $\mathrm{~A} 1 \mathrm{~B} 2 \mathrm{C} 2$ & $\mathrm{~A} 2 \mathrm{~B} 1 \mathrm{C} 2$ & $\mathrm{~A} 2 \mathrm{~B} 2 \mathrm{C} 2$ \\
\hline & Total & \multicolumn{2}{|c|}{ A1 } & \multicolumn{2}{|c|}{$\mathrm{A} 2$} \\
\hline
\end{tabular}

\section{Description:}

A1B1C1 :The method of training a whole using a form ofexercises stretching static. groups of students who have grip strength above average.

A1B1C2 : The overall training method uses a form ofexercise for stretching staticgroups of students who have below average grip strength.

A1B2C1 : The overall training method uses a form ofexercise for stretchingdynamic groups of students who have above average grip strength.

A1B2C2 : The overall training method uses a form ofexercise for stretchingdynamic groups of students who have below average grip strength.

A2B1C1 : The section training method uses a form ofexercise for stretching staticgroups of students who have above average grip strength.

A2B1C2 : The section training method uses a form ofexercise for stretching staticgroups of students who have below average grip strength.

A2B2C1 : The section training method uses a form ofexercise for stretching dynamicgroups of students who have above average grip strength.
A2B2C2 : The section training method uses a form ofexercise for stretching dynamicgroups of students who have below average grip strength.

A1 : Overall training method

A2 : Parttraining method

B1 : stretching Static

B2 : stretching Dynamic

B1 : Grip strength above average

B2 :strength below average Grip

This research was carried out at the FKOR UNS Tennis Court. Data collectiontechniques in this study are: (1) For the dependent variable data obtained through 3 tests of the motion assessment ofserve technique skills flat tennis field, (2) fordata attribute variableobtained through the test of curvature and grip strength.

The sample in this study was obtained from an affordable population, that isstudents who have passed tennis courses as many as 200 students. The research sample was determined by thetechnique Randomized group design. 
Tabel 2. Grouping Experiment Samples with a block system

\begin{tabular}{|c|c|c|c|c|c|}
\hline & & \multicolumn{4}{|c|}{ Training Method (A) } \\
\hline \multirow{2}{*}{\multicolumn{2}{|c|}{$\begin{array}{l}\text { Stretching } \\
\text { (B) }\end{array}$}} & \multicolumn{2}{|c|}{ Overall (A1) } & \multicolumn{2}{|c|}{ Section (A2) } \\
\hline & & Static (B1) & $\begin{array}{l}\text { Dynamic } \\
\text { (B2) }\end{array}$ & Static (B1) & Dynamic (B2) \\
\hline \multirow{2}{*}{ Grip Strength } & Above Average (C1) & 10 & 10 & 10 & 10 \\
\hline & Below Average (C2) & 10 & 10 & 10 & 10 \\
\hline \multicolumn{2}{|c|}{ Total } & 20 & 20 & 20 & 20 \\
\hline
\end{tabular}

This research plan held on the tennis court FPOK UNS for six weeks or 18 (eighteen) meetings with a frequency of training three times a week. The treatment methods given are the overallmethod andmethod trainingthe part trainingbased on each group.

The analysis techniques used in this study are as follows $^{11,12}$ :

1) To test the statistical hypothesis the twolaneVariance (ANAVA) analysis technique was used $2 \times 2 \times 2$ at the significance level $\alpha=0.05$.

2) To test the normality of the data obtained from the learning outcomes of tennisserveskills Courtused the Lilliefors test.

3) To test homogeneity using the Bartlett test.

4) If there is an interaction between the training methods and motivation on the learning outcomes of the tennis flat serve skills, will be followed by the Tukey Test.

\section{Results and Discussion}

Based on the experimental design in this study, there were 6 (six) groups sample that had scores on the results of a serve skills test flat on a tennis court game that needed to be described separately. The following after the presentation of table 3 is a description of scores of theserve skills test results flat in the playing field tennis of the six groups mentioned.

Table 3. Description data result testflat serve

\begin{tabular}{|c|c|c|c|c|c|c|c|c|}
\hline No. & KLP & N & Range & Min. & Max. & Sum & Mean & Std. Deviation \\
\hline 1 & A1 & 40 & 44.34 & 33.89 & 78.23 & 2045.34 & 51.1335 & 10.90200 \\
\hline 2 & A2 & 40 & 39.41 & 33.89 & 73.30 & 1973.90 & 49.3475 & 9.18314 \\
\hline 3 & B1 & 40 & 33.43 & 42.72 & 76.15 & 2276.97 & 56.9243 & 10.62138 \\
\hline 4 & B2 & 40 & 42.56 & 30.22 & 72.78 & 1846.47 & 46.1618 & 10.29003 \\
\hline 5 & C1 & 40 & 30.05 & 38.13 & 68.18 & 2186.09 & 54.6522 & 8.13529 \\
\hline
\end{tabular}




\begin{tabular}{|c|c|c|c|c|c|c|c|c|}
\hline 6 & $\mathrm{C} 2$ & 40 & 31.41 & 30.71 & 62.12 & 1814.02 & 45.3505 & 9.59355 \\
\hline 7 & $\mathrm{~A} 1 \mathrm{~B} 1 \mathrm{C} 1$ & 10 & 16.07 & 48.99 & 65.06 & 568.50 & 56.8500 & 5.25667 \\
\hline 8 & $\mathrm{~A} 2 \mathrm{~B} 1 \mathrm{C} 1$ & 10 & 12.42 & 49.05 & 61.47 & 542.23 & 54.2230 & 3.77874 \\
\hline 9 & A1B1C2 & 10 & 13.66 & 49.66 & 63.32 & 544.11 & 54.4110 & 4.47667 \\
\hline 10 & A2B1C2 & 10 & 11.78 & 46.06 & 57.84 & 514.64 & 51.4640 & 3.35061 \\
\hline 11 & A1B2C1 & 10 & 16.81 & 41.29 & 58.10 & 489.76 & 48.9760 & 4.51198 \\
\hline 12 & A2B2C 10 & 18.64 & 45.04 & 63.68 & 504.70 & 50.4700 & 5.79869 \\
\hline 13 & A1B2C2 & 10 & 11.14 & 39.78 & 50.92 & 454.86 & 45.4860 & 3.57533 \\
\hline 14 & A2B2C2 & 10 & 12.57 & 36.75 & 49.32 & 428.80 & 42.8800 & 3.66810 \\
\hline
\end{tabular}

The results of this study consisted of testing the hypothesis using a factorial designperformed with variant analysis. The results of his research are as follows:

Table 4. Recapitulation of ANAVA Results in Next Stage with Tukey Test

\begin{tabular}{|c|c|c|c|c|c|}
\hline No & $\begin{array}{c}\text { Hypothesis Group } \\
\text { are Compared }\end{array}$ & Qcount & Qtable & Sig. & Description \\
\hline 1 & A1 dan A2 & 9,362 & 5,305 & .000 & There is a difference \\
\hline 2 & B1 dan B2 & 9,362 & 5,305 & .000 & There is a difference \\
\hline 3 & C1 dan C2 & 9,362 & 5,305 & .000 & There is a difference \\
\hline
\end{tabular}

Based on table 4, it can be concluded that the hypothesis of the eleven are overall there is a significant difference between the training methods, the form of exercises stretching and the strength of grips onserve skills flat in FKOR students UNS Surakarta both using stretching static and dynamic and using aboveaverage grip strength and below-average grip strength. Furthermore, the results of the research can be elaborated on the discussion of each hypothesis in accordance with the theory that supports the results of this study.

After analyzing the data using the Variance Analysis approach Factorial and followed by test Tukey's of the eleven research hypotheses submitted. Research findings are the results of statistical data analysis that need to be studied further to be able to explain why there are accepted hypotheses, hypotheses that are rejected, and why there are significant interactions between curvature and grip strength on flat serve skills.

The overall training method is better than the training method section on serve skills

Based on the results of the analysis of the testTAKEY $(Q)$ data differences in the overall and training section against serve skills flat, obtained differences in 
the average value or the value of Q-count 9.3362 and Q-table 5.305 significant difference sig (p) is smaller than $0.05(0,000<0.05)$, to be seen in the Sig column table (p ) is 0,000 , or the probability is well below $\alpha$ 0.05 . So that a decision can be made that reject $\mathrm{H} 0$ and accept H1. So, it can be concluded that the training method overall is better than the part training method on serve skills flat.

The results of this calculation show that overall skill scores the serve flat in the training process using the overall training method are better than the section training method, in other words the use of methods different will result serve skill score flat in a in training processes different. Therefore, according to the description and discussion of the strengths of the overall training method and the part training method, the overall training method is better than the part training method to improve serve skills flat in serve training flat in tennis court games.

The form ofexercises stretching staticis better than the form ofexercises stretching dynamiconserve skills.

Based on the results of the analysis of the Tukey test (Q) data on the differences in the form ofexercises stretching static and the form of exercises stretching dynamic onserve skills flat, different mean values Q-count 9,362 and Q-table 5,305 significantdifference sig (p) is smaller than $0.05(0,000<0.05)$, to be seen in the column table Sig (p)is 0,000 , or the probability is far below $\alpha 0,05$. So, decision can be made that areject H0andaccept H1. So, it can be concluded that there are differences serve skills flat in playing tennis between thetraining stretching staticgroup and thetraining group stretching dynamicin FKOR UNS students. This proves $\mathrm{H} 1: \mu \mathrm{B} 1>\mu \mathrm{B} 2$ so that a decision can be made that reject $\mathrm{H} 0$ and accept $\mathrm{H} 1$. So it can be concluded that theserve skills flat in a group of students with a form ofexercises stretching staticare better than the form ofexercises stretching dynamicin applyingserve training materials flat at school.

The results of this calculation indicate that the overall score ofskills serve flat using a form ofexercises stretching staticis better than the form ofexercises stretching dynamic, in other words a different form of exercise will produceserve skills flat different. Therefore, in accordance with the description and discussion of the form ofexercises stretching staticandforms ofexercises stretching dynamic, then the overall form ofexercises stretching staticis better than the form ofexercises stretching dynamicto improve the results ofserve skills flat in playing tennis ${ }^{13}$.

The grip strength above average is better than thestrength gripbelow average forserve skills.

Based on the test results of the Tukey Test (Q) data, the differencestrength is in gripabove average and the grip strength is below average for serve skills flat, obtained differences in the average value or Q-value ofcount 9,362 and Q-table of 5,305 differences the real $\operatorname{sig}(p)$ is smaller than $0.05(0,000<0.05)$, to be seen in the column table $\operatorname{Sig}(\mathrm{p})$ is 0,000 , or the probability is far below $\alpha 0.05$. So, can that a decisionbe made that reject $\mathrm{HO}$ and accept H1. So, it can be concluded that there are differencesserve skills flat in playing tennis between groupsmethods of the grip strength trainingabove the average and thestrength training method groups gripbelow the average in FKOR UNS students.

So, it can be concluded that theserve skills flat in groups of students with high grip strength are better than belowgrip strength average. This proves $\mathrm{H} 1: \mu \mathrm{C} 1>$ $\mu \mathrm{C} 2$, so that a decision can be made that reject $\mathrm{H} 0$ and accept H1. So, it can be concluded that theserve skills flat in a group of students who have grip strength above average is better than grip strength below average.

The results of this calculation show that the overall score of theskill serve flat that uses above average grip strength is better than the below average grip strength, in other wordsgrip strength differentwill resultserve skills flat in different. Therefore accordingly, with the description and discussion of grip strength above average and grip strength below average, then overall grip strength above average is better than grip strength below average to increase yield servicing skills Flat in playing tennis ${ }^{14}$.

\section{Conclusion}

From the results of hypothesis testing and discussion 
of the results of the study,can be drawn the following conclusions:

1. There is a significant difference between the overallmethod andmethodtrainingthe section trainingon theserve skills flat tennisof FKOR UNSstudents.

2. There is a significant difference between the forms of stretching exercises static with theform of dynamic stretching exercises for field tennis flat serve skillsstudents FKOR UNS.

3. There is a significant difference between the grip strength above the average grip strength below the average to the serve skills flat tennis court FKOR UNS Surakarta students.

Ethical Clearance: This research has received approval from the Etik Health Research Commission, Universitas Negeri Semarang with Document Number: 115 / KEPK / EC / 2019. This research has met the principles stated in the Standards and Operational Guidance for Ethics Review of Health-related Research with Human Participants from WHO 2011 and the International Ethical Guidelines for Health-related Research Involving Humans from CIOMS and WHO 2016.

Source of Funding: This research was funded by self.

Conflict of Interest: The authors declare no potential conflict of interest.

\section{References}

1. Tudor OB. Teory and Metodologi Of Training. Iowa: Kendall/Hunt Publishing Company Dubugue;2009.

2. James Tangkudung. Kepelatihan Olahraga, Pembinaan Prestasi Olahraga. Jakarta: Cerdas Jaya;2012

3. Fu MC, Ellenbecker TS, Renstrom PA, Windler GS, Dines DM. Epidemiology of injuries in tennis players. Curr Rev Musculoskelet Med. 2018;11(1):1-5. doi: 10.1007/s12178-018-9452-9. PMID: 29340975; PMCID: PMC5825333..
4. Delphine Chadefaux, Guillaume Rao, JeanLoïc Le Carrou, Eric Berton \& Laurent Vigouroux. The effects of player grip on the dynamic behaviour of a tennis racket, Journal of Sports Sciences.2017;35(12):1155-1164, DOI: 10.1080/02640414.2016.1213411.

5. ITF. Buku Panduan Pelatih ITF level 1 Couches Course. Makassar; 2005

6. Bahamonde RE, Knudson D. Kinetics of the upper extremity in the open and square stance tennis forehand. J Sci Med Sport. 2003;6(1):88-101. doi: 10.1016/s1440-2440(03)80012-9. PMID: 12801214 .

7. Elliott B, Fleisig G, Nicholls R, Escamilia R. Technique effects on upper limb loading in the tennis serve. J Sci Med Sport. 2003;6(1):76-87. doi: 10.1016/s1440-2440(03)80011-7. PMID: 12801213.

8. Baszczyński P, Chevrel-Fraux C, Ficheux S, Manin L, Triquigneaux S. Settings Adjustment for String Tension and Mass of a Tennis Racket Depending on the Ball Characteristics: Laboratory and Field Testing. Procedia Eng. 2016;147: 472-477. doi: 10.1016/j.proeng.2016.06.343.

9. Lisa Ferrara, Anders Cohen. A mechanical study on tennis racquets to investigate design factors that contribute to reduced stress and improved vibrational dampening. Procedia Eng. 2013;60: 397-402. doi: 10.1016/j.proeng.2013.07.015.

10. Mahendra, Agus. Modul Teori Mengajar Motorik, Bandung: FPOK UPI Bandung; 2007

11. Hasan, Misbahuddin, Iqbal. Analisis data penelitian dengan Statistik, Jakarta: Bumi Aksara; 2013

12. Kadir. Statistika untuk penelitian ilmu-ilmu social. Jakarta: Pustaka Pelajar; 2010

13. Kovacs M, Ellenbecker T. An 8-stage model for evaluating the tennis serve: Implications for performance enhancement and injury prevention. Sports Health. 2011;3: 504-513. doi: 10.1177/1941738111414175.

14. Van Der Hoeven H, Kibler WB. Shoulder injuries in tennis players. Br. J. Sports Med. 2006; 40:435440. doi: 10.1136/bjsm.2005.023218. 